\title{
Identification of Yeasts and Evaluation of their Distribution in Taiwanese Kefir and Viili Starters
}

\author{
S. Y. Wang, ${ }^{*}$ H. C. Chen, $†$ J. R. Liu, † Y. C. Lin, $†$ and M. J. Chen $† \S^{1}$ \\ ${ }^{*}$ Experimental Farm, \\ †Department of Animal Science and Technology, \\ †Institute of Biotechnology, and \\ $\S R$ esearch Center of Food and Biomolecules, National Taiwan University, Taipei, Taiwan, Republic of China
}

\begin{abstract}
The objective of the present study was to investigate yeast communities in kefir grains and viili starters in Taiwan through conventional microbiological cultivation and polymerase chain reaction-denaturing gradient gel electrophoresis (PCR-DGGE). The DNA sequencing was used as a validity technique to ensure that all isolates within each group belonged to just one species, and to confirm the identified results of PCRDGGE. Results indicated that a combination of conventional microbiological cultivation with PCR-DGGE and sequencing could successfully identify 4 yeast species from both types of cultures in Taiwan. Kluyveromyces marxianus, Saccharomyces turicensis, and Pichia fermentans were found in Taiwanese kefir grains with a distribution of 76,22 , and $2 \%$, respectively, whereas Klu. marxianus, Saccharomyces unisporus and P. fermentans were identified in viili starters corresponding to 58,11 , and $31 \%$ of the total cell counts, respectively. Furthermore, the culture-independent method was applied to identify the yeast species using DGGE. Only 2 yeast species, $K l u$. marxianus and $S$. turicensis, were found in kefir grains and 2, Klu. marxianus and $P$. fermentans, in viili starters. These results suggest that in samples containing multiple species, PCR-DGGE may fail to detect some species. Sequences of yeast isolates reported in this study have been deposited in the GenBank database under accession nos. DQ139802, AF398485, DQ377652, and AY007920.
\end{abstract}

Key words: yeast, kefir grain, viili, denaturing gradient gel electrophoresis

\section{INTRODUCTION}

With different cultural origins, sources, and processing methods, soured milk has diversified into a variety of products such as dahi, dadih, kefir, koumiss, långfil,

Received June 21, 2007.

Accepted June 8, 2008.

${ }^{1}$ Corresponding author: cmj@ntu.edu.tw and viili (Mistry, 2004; Chen et al., 2006; Dharmawan et al., 2006). Kefir originated in the Caucasus mountains of Russia centuries ago and has been credited with various health-promoting properties (Liu et al., 2002, 2006a,b). This cultured milk beverage results from the microbial action of a community of microorganisms present in kefir grains in milk. Kefir has a uniform, creamy consistency and a slightly acidic taste caused mostly by lactic acid, along with some effervescence due to carbon dioxide, a low $(<2 \%$, vol $/ \mathrm{vol})$ concentration of ethanol because of the action of yeast cells present in the grains, and a variety of aromatic substances, including acetaldehyde, acetoin, and diacetyl, that imparts its characteristic flavor (Farnworth and Mainville, 2003). Viili is a ropy, fermented milk that originated in Scandinavia, which is claimed to have various functional benefits and health-improving potential (Kitazawa et al., 1991, 1993, 1996; Nakajima et al., 1992; Ruas-Madiedo et al., 2006). Unlike kefir grains, viili starters do not form grains. This cultured milk beverage is made with the microbial action of lactic acid bacteria mainly composed of Lactococcus lactis ssp. cremoris exopolysaccharide-producing strains and a surface-growing, yeast-like fungus, Geotrichum candidum (Tsutsui et al., 1998; Leporanta, 2003; Boutrou and Guéguen, 2005). Most traditional viili cultures also contain yeasts. The effect of yeasts in viili is not clear, but it is believed that yeasts in viili could provide the unique flavor and enhance lactic acid bacteria to produce exopolysaccharides.

To better understand the fermentation process and to evaluate the health benefits of both fermented products, researchers have identified the various bacteria and yeasts in kefir grains and viili starters using selective growth medium, morphological, and biochemical characteristics (Tsutsui et al., 1998; Lin et al., 1999; Simova et al., 2002; Leporanta, 2003; Shurtleff and Aoyagi, 2004; Witthuhn et al., 2004). However, such media are not necessarily suited to the growth of all microorganisms present in kefir grains or viili starters. Fujisawa et al. (1988) observed that Lactobacillus kefiranofaciens grew on kefir grain polysaccharide- 
producing Lactobacillus (KPL) agar, but not on Briggs liver (BL) agar or de Man, Rogosa, and Sharpe (MRS) agar. Farnworth and Mainville (2003) compared MRS, KPL, and Rogosa-CW to lactic acid whey medium and found that lactic acid whey medium yielded better growth rates for the lactobacilli present in kefir grains. In addition, some studies revealed that many of the microorganisms isolated are closely related and therefore challenging to isolate and identify.

Although culture-dependent methods are more widely used for microorganism identification, cultureindependent methods, which do not require the microorganisms to be cultured in media, have important advantages over their culture-dependent analogs. Over the past decade, culture-independent identification techniques based on genotype have multiplied, with different techniques displaying differences in discriminatory power, reproducibility, and workload. Of those techniques, PCR combined with denaturing gradient gel electrophoresis (DGGE) has proven to be a useful method for analyzing complex microbial populations that does not require prior separation of individual inhabitants (Muyzer and Smalla, 1998; Ercolini, 2004). This method has been used successfully to evaluate bacterial composition of probiotic products (Fasoli et al., 2003), identify probiotics in South African products (Theunissen et al., 2005), profile the yeast populations in raw milk (Cocolin et al., 2002), investigate yeast populations associated with Ghanaian cocoa (Nielsen et al., 2005), determine yeast species involved in fermentation of Coffea arabica in East Africa (Masoud et al., 2004), differentiate Lactobacillus species present in the gastrointestinal tract (Walter et al., 2000), and identify the microbial community present in the South Africa and Irish kefir grains (Garbers et al., 2004). On the other hand, several studies (Felske et al., 1998; Fasoli et al., 2003; Prakitchaiwattana et al., 2004; Theunissen et al., 2005) indicated that minor species may not be detected by PCR-DGGE when present at $<1 \%$ of the total population (Renouf et al., 2007).

Because safety and quality control are crucial for kefir and viili products, investigation of their microbiological profiles is important. The presence of yeasts in kefir grains and viili starters not only plays a key role in the fermentation process and in forming the flavor and aroma of these fermented milks, but also stimulates lactic acid bacteria to enhance exopolysaccharide production (Cheirsilp et al., 2003). Although many yeast species have been identified in kefir grains and in the final products (Farnworth and Mainville, 2003) based on phenotypic properties (Rohm et al., 1992; Pintado et al., 1996; Lin et al., 1999), RFLP analysis, DNA/DNA hybridization (Wyder and Puhan, 1997; Wyder et al., 1999), and PCR-DGGE (Garbers et al., 2004), none of the yeast species in Taiwan kefir grains and viili starters have been determined by culture-independent methods. Thus, the purpose of this study was to identify species of yeast and to study their distribution in kefir grains and viili starters in Taiwan through conventional microbiological cultivation and PCR-DGGE. The DNA sequencing was used as a validation technique to ensure that all isolates within each group belonged to just one species and to confirm the identified results of PCR-DGGE.

\section{MATERIALS AND METHODS}

\section{Kefir Grains and Viili Starters}

Kefir grains and viili starters were collected from Hsinchu and Taipei (2 cities in northern Taiwan), respectively (Lin et al., 1999). In the laboratory, kefir grains and viili starters were inoculated $(5 \%, \mathrm{wt} / \mathrm{vol})$ and propagated in sterilized milk at $20^{\circ} \mathrm{C}$ for $20 \mathrm{~h}$. The grains were retrieved by sieving, reinoculated into fresh milk, and incubated at $20^{\circ} \mathrm{C}$ for $20 \mathrm{~h}$. The viili starters $(5 \%, \mathrm{wt} / \mathrm{vol})$ were transferred into fresh milk, and incubated at $20^{\circ} \mathrm{C}$ for $20 \mathrm{~h}$. After this procedure was repeated 3 times, the grains were considered active and used in this study.

\section{Isolation and Enumeration of Microorganisms}

Ten grams each of kefir grains and viili starters were homogenized in $90 \mathrm{~mL}$ of sterile saline solution $(0.85 \%$ sodium chloride solution, $\mathrm{pH}$ 5.5) in a Stomacher (Laboratory blender stomacher 400, Seward, London, UK) until no grain particles were observed. Concentrations of the viable yeasts in suspensions were obtained by serial plating dilutions. Yeasts and molds were examined on potato dextrose agar (Difco Laboratories, Detroit, MI), with $100 \mathrm{mg} / \mathrm{kg}$ chlortetracycline (Sigma, St. Louis, MO) to inhibit the growth of bacteria. The plates were incubated at $25^{\circ} \mathrm{C}$ for $3 \mathrm{~d}$ (Lin et al., 1999) and enumerated.

\section{Reference Strains}

The reference strains used for this study, including Kluveromyces marxianus var. marxianus (BCRC 20330), Saccharomyces cerevisiae (BCRC 21685), Saccharomyces turicensis (BCRC 22968), Saccharomyces unisporus (BCRC 21975) and Pichia fermentans var. fermentans (BCRC 22090), were obtained from the Bioresource Collection and Research Center of the Food Industry Research and Development Institute in Hsinchu, Taiwan. 


\section{The Harrison Disc Method}

The Harrison disc method was adopted from Harrigan (1998). This method was used to determine the prevalent microbes that developed on each dilution and to select representative colonies from each plate in a random statistical manner for further purification and identification. The Harrison disc method can calculate the distribution of various microorganisms present in a sample.

\section{DNA Isolation}

Ten grams each of kefir grains and viili starters were homogenized in a Stomacher as described previously. After homogenization, $1 \mathrm{~g}$ each of sample was centrifuged at $5,000 \times g$ for $10 \mathrm{~min}$. The pellets were suspended in $500 \mu \mathrm{L}$ of sorbitol reaction solution [1 M sorbitol (Merck, Darmstadt, Germany), $100 \mathrm{~m} M$ EDTA (Merck), $14 \mathrm{mM}$ B-mercaptoethanol (Merck), $200 \mathrm{U}$ of lyticase (Merck)] and incubated at $30^{\circ} \mathrm{C}$ for $30 \mathrm{~min}$ before centrifuging at $5,000 \times g$ for $5 \mathrm{~min}$. The pellets were subjected to DNA extraction using the Blood and Tissue Genomic DNA Extraction Miniprep System (Viogene-Biotek Co., Taipei, Taiwan). This system included protein lysis and isolation of genomic DNA. The pellets were first lysed by proteinase K. Genomic DNA was then isolated by silica-gel-membrane technology and centrifugation. Finally, pure DNA was eluted in double-distilled $\mathrm{H}_{2} \mathrm{O}$.

\section{API 20C System}

The API 20C system (bioMérieux, Marcy l'Etoile, France) includes 21 assimilation tests for carbohydrates and includes a database of 47 different species. All yeast identification procedures were conducted in accordance with the manufacturer's instructions. The reactions were examined visually and determined to be positive or negative based on the presence or absence of turbidity in the carbohydrate wells.

\section{DNA Amplification}

The DNA amplification was modified using the method of Cocolin et al. (2002). The D1 region of the 26S rRNA gene was amplified by PCR using the primers NL1GC (5'-GCG GGC CGC GCG ACC GCC GGG ACG CGC GAG CCG GCG GCG GGC CAT ATC AAT AAG GGG AGG AAA AG-3') (the GC clamp is underlined) and a reverse primer LS2 (5'-ATT CCC AAA CAA CTC GAC TC-3') (Cocolin et al., 2000). The PCR was carried out in a total volume of $50 \mu \mathrm{L}$ containing $20 \mathrm{mM}$ Tris $\mathrm{HCl}$ (Sigma), $10 \mathrm{~m} M \mathrm{KCl}$ (Sigma), $2 \mathrm{~m} M \mathrm{MgCl}_{2}$
(Merck), $0.1 \mathrm{~m} M$ dNTPs (Promega, Madison, WI), 0.2 $\mathrm{m} M$ of the primers, 1.25 IU of Taq polymerase (Yeastern Biotech, Taipei, Taiwan), and $1 \mu \mathrm{L}$ of the extracted DNA (300 $\mathrm{ng} / \mu \mathrm{L})$.

The PCR products $(250 \mathrm{ng} / \mathrm{\mu L})$ were generated using an initial denaturation step of $5 \mathrm{~min}$ at $95^{\circ} \mathrm{C}$ followed by 30 cycles of denaturation at $95^{\circ} \mathrm{C}$ for $60 \mathrm{~s}$, annealing at $52^{\circ} \mathrm{C}$ for $45 \mathrm{~s}$, and elongation at $72^{\circ} \mathrm{C}$ for $60 \mathrm{~s}$. A final chain extension was done for $8 \mathrm{~min}$ at $72^{\circ} \mathrm{C}$. Amplified products were run on a $2 \%$ agarose gel (Nippon Gene Co., Tokyo, Japan), stained with ethidium bromide (Fluka and Riedel, St. Gallen, Switzerland), and visualized under UV light.

\section{DGGE}

The PCR fragments were separated by DGGE using the BioRad DCode Universal Mutation Detection System (Bio-Rad Laboratories, Hercules, CA). Separation of the PCR amplicons was obtained by the direct application of $20 \mu \mathrm{L}$ of PCR products onto 9\% (wt/ vol) polyacrylamide gels (Bio-Rad) in 50× Tris-acetate EDTA buffer containing a linear denaturant gradient of between 30 and $55 \%$ [100\% corresponds to $7 M$ urea (Merck) and 40\% wt/vol formamide (Merck)]. Electrophoresis was performed at a constant voltage of $200 \mathrm{~V}$ at $60^{\circ} \mathrm{C}$ for $3.5 \mathrm{~h}$. After migration, the gel was stained with $0.25 \mathrm{\mu g} / \mu \mathrm{L}$ ethidium bromide (Fluka and Riedel) for $15 \mathrm{~min}$ and the fragments were visualized under UV light. The PCR-DGGE technique to identify the microorganisms present in kefir grains and viili starters was conducted by comparing the PCR-DGGE patterns obtained from the analyzed products with the reference strains. The DGGE reference markers were amplicons obtained from 5 yeast species in equal amounts.

\section{Sequencing of PCR-Amplified 26S rDNA Region}

In this study, randomly selected isolates from each group, whose number was equal to the square root of the number of isolates in that group, were identified to ensure that all isolates within each group belonged to just one species, and to verify the PCR-DGGE results. Identification was performed by sequencing the $5^{\prime}$ end of the 26S rDNA encompassing the D1 and D2 expansion domains using the primers NL1 (5'-GCAT ATC AAT AAG GGG AGG AAA AG-3') and a reversed primer NL4 (5'-GGTCCGTGTTTCAAGACGG-3') (O'Donnell, 1993). Amplification was performed for 36 PCR cycles with annealing at $52^{\circ} \mathrm{C}$, extension at $72^{\circ} \mathrm{C}$ for $2 \mathrm{~min}$, and denaturation at $94^{\circ} \mathrm{C}$ for $1 \mathrm{~min}$. All PCR products amplified with primers designed for yeasts were sequenced for species identification. The PCR products were purified with the Concert Rapid PCR Purification 
system (QIAquick Gel Extraction Kit, Qiagen Inc., Valencia, CA), and DNA concentration was checked on a spectrophotometer. These DNA products (10 ng/ $\mu \mathrm{L})$ were sent for sequencing. Sequencing was carried out at the Genedragon Co. (Taipei, Taiwan) using a 373A automated gene sequencer (Applied Biosystems, Foster City, CA). The DNA sequence similarity was determined using the National Center for Biotechnology Information BLAST 2.0 program (http://www.ncbi. nlm.nih.gov/BLAST/).

\section{RESULTS AND DISCUSSION}

\section{Culture-Dependent and Culture-Independent Methods}

The yeast counts for kefir grains and viili starters were $2.32 \times 10^{7} \mathrm{cfu} / \mathrm{g}$ and $2.67 \times 10^{7} \mathrm{cfu} / \mathrm{g}$, respectively. Using the Harrison disc method, 91 colonies were isolated in kefir grains and 124 colonies in viili starters, which were classified by PCR-DGGE. The PCR-DGGE profiles indicated that 3 different yeast strains (named HY1, HY2, and HY3) were found in kefir grains (Figure 1a), and another 3 species (named TY1, TY2, and TY3) were observed in viili starters (Figure 1b).

Because many plating procedures are partly selective and exclude part of the microbial community, the DNA of yeast species in kefir grains and viili starters were extracted and directly identified by PCR-DGGE. Results (Figure 2) indicated that kefir grains contained HY1 and HY2 stains; HY3, located previously by the culture-dependent method, was not identified. Similarly, only 2 yeast species were found in viili starters (TY1 and TY3); TY2 was not discovered.

Culture-independent methods directly using PCRDGGE did not require microorganisms to be cultivated in specific media; thus, one might expect to detect a greater diversity of yeast species in kefir grains and viili starters using PCR-DGGE. On the contrary, fewer varieties of yeast species were identified directly by PCR-DGGE than were found with the use of initial enrichment on nutritive media. Levels of detection are often around $10^{3}$ to $10^{4} \mathrm{cfu} / \mathrm{mL}$, but counts of $10^{2} \mathrm{cfu} / \mathrm{mL}$ have been reported (Cocolin et al., 2000; Prakitchaiwattana et al., 2004; Nielsen et al., 2005). The detection limit of individual yeast species in mixed populations, however, was also determined by their relative populations. Prakitchaiwattana et al. (2004) provided information on mixed species populations such that when the ratio of major to minor species exceeds 100 fold, the low-population species will not be detected. Species with larger populations in the mixture might give greater amounts of template DNA and, therefore, have a greater probability of being detected (Prakitchaiwat-
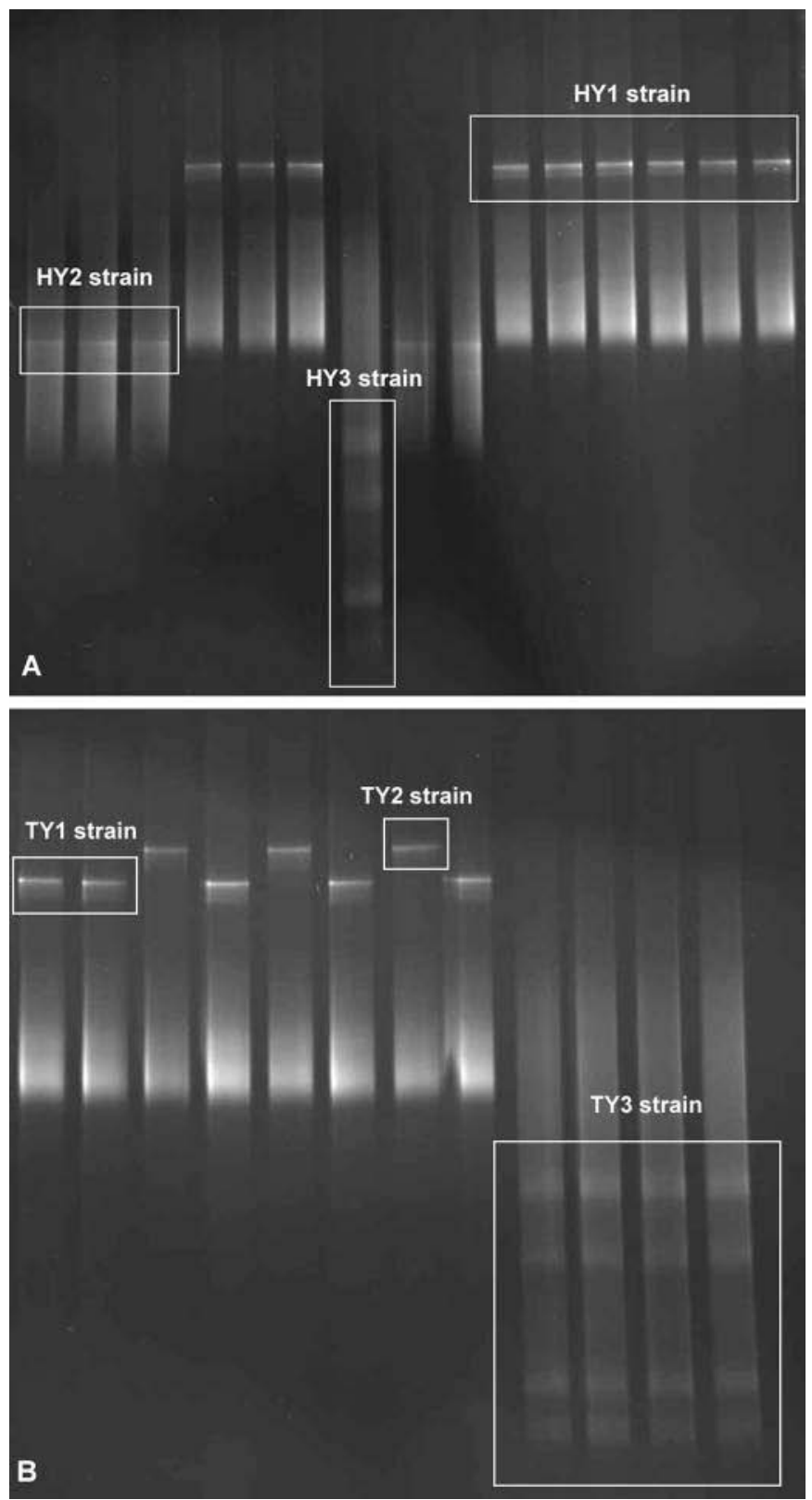

Figure 1. Classification of yeasts isolated from kefir grains (A) and viili starters (B) by PCR-denaturing gradient gel electrophoresis.

tana et al., 2004). Thus, the purity and concentration of template DNA become more important when analyzing yeast cells associated with food. Moreover, high quantities of competitor templates would also interfere with detection (Theunissen et al., 2005). Kefir grains and viili starters contain large amounts of DNA from other microbial groups that has the potential to interfere with the specific PCR-amplification of yeast DNA and compromise the reliability and quality of the data obtained by DGGE. 


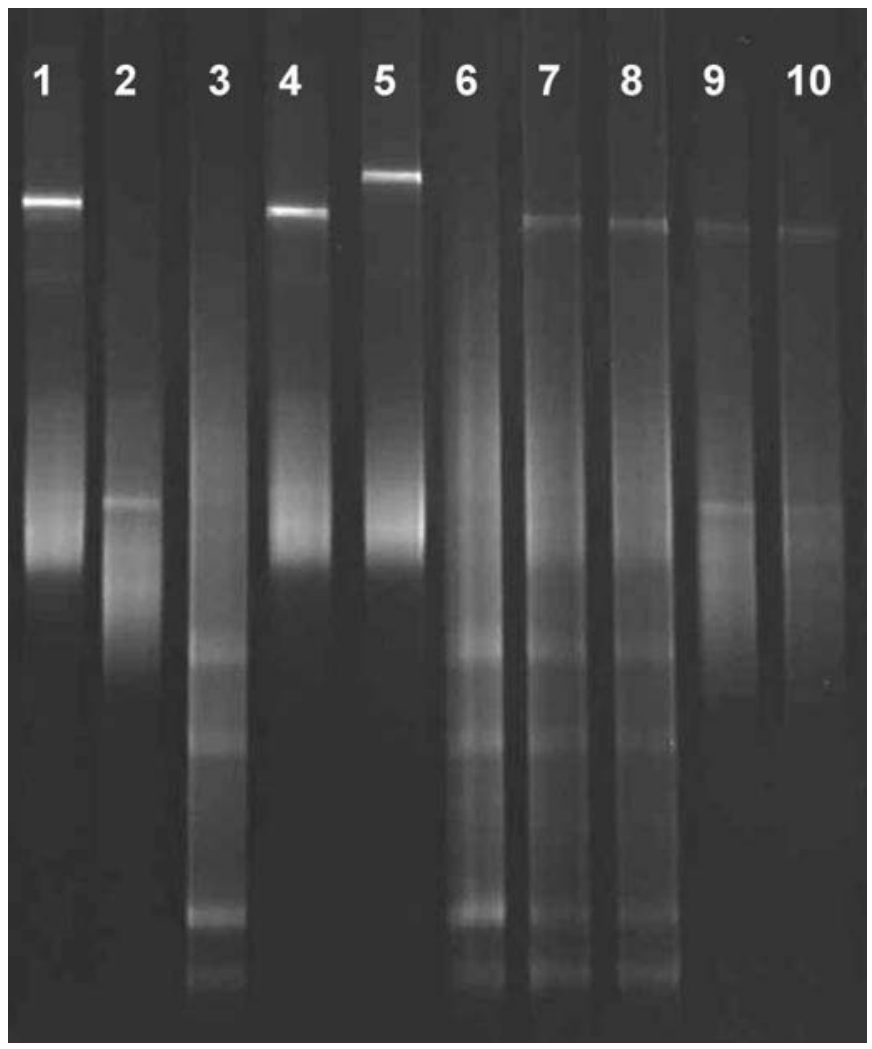

Figure 2. Denaturing gradient gel electrophoresis profiles of the PCR products obtained from the DNA extracted directly from kefir grains (HY1, 2, and 3) and viili starters (TY1, 2, and 3). Lane $1=$ HY1; lane 2 = HY2; lane 3 = HY3; lane 4 = TY1; lane 5 = TY2; lane 6 $=$ TY3; lanes 7 and $8=$ viili starter; lanes 9 and $10=$ kefir grain.

\section{Identification of Isolates}

For identification of isolated yeast species, the API 20C system, PCR-DGGE, and DNA sequencing methods were applied. Results in Table 1 indicate that, except for HY3 and TY3, yeasts isolated from both starters could degrade D-galactose. On the other hand, only HY1 from kefir grains and TY1 from viili starters could metabolize D-lactose. Both HY1 and TY1 showed very similar assimilation of carbohydrates. They were identified as Candida famata, whereas TY3 and HY3 were determined to be Rhodotorula minua. Strains HY2 and TY2 were not identified by this method. Accuracy of identification for the API 20C system has varied from 88\% (Davey et al., 1995) to 99\% (Fenn et al., 1994). Although this method is effective for identifying relatively common yeasts, its application is more limited for accurate identification of less frequently recovered taxa (Ramani et al., 1998).

The results of yeast identification by DGGE are shown in Figure 3. The expected 250-bp (including 40 GC clamp) PCR fragments were successfully amplified from all reference and sample strains. As reported, Klu. marxianus var. marxianus (lane 1), S. cerevisiae (lane 2), S. turicensis (lane 3), S. unisporus (lane 4), and $P$. fermentans var. fermentans (lane 5) gave specific patterns in the DGGE gel, allowing identification of these yeast species. Pichia fermentans var. fermentans presented several DGGE bands. Although the reasons for multiple banding within the one species are not well understood (Beh et al., 2006), those multiple bands would allow precise species identification by DGGE. There are a couple of studies (Masoud et al., 2004; Prakitchaiwattana et al., 2004) in which multiple bands have been found for the one yeast species. One of the studies (Masoud et al., 2004) also reported multiple DGGE bands for Pichia spp., which was similar to our findings.

The DGGE patterns obtained by PCR-based DGGE analysis of the isolates from kefir grains (lanes 7 to 9) and viili starters (lanes 10 to 12) are also shown in Figure 3. Band positions of the unknown sample lane were compared visually with reference band positions. Our observations indicated that kefir grains contained Klu. marxianus var. marxianus (HY1, lane 7 ) and $S$. turicensis (HY2, lane 8), whereas viili starters included Klu. marxianus var. marxianus (TY1, lane 10) and $S$. unisporus (TY2, lane 11). All strains belonging to the same species showed the same migration in the gel. The DGGE patterns of HY3 and TY3 were very similar to the patterns of $P$. fermentans var. fermentans (lane 5 ), forming several lower bands, but the migration of bands was different. Further identification of HY3 and TY3 was necessary.

To confirm the PCR-DGGE identified results and ensure that all isolates within each group belonged to just one species, the PCR-amplified D1/D2 domain of $26 \mathrm{~S}$ rDNA region was sequenced. After alignment using BLAST, the DNA sequences of yeasts isolated from kefir grains and viili starters showed 99 to 100\% identity (Table 1) with the sequences retrieved from GenBank. No differences were observed between results from DNA sequencing and PCR-DGGE in detecting yeast species, but a distinct result was found using API. These 4 yeasts (Klu. marxianus, $S$. turicensis, $P$. fermentans, $S$. unisporus) identified by PCR-DGGE and sequencing were not listed in the API 20C database, but the biocodes of these isolates generated patterns similar to other species listed in the API 20C database and yielded a false identification. In addition, it is interesting to note that HY3, TY3, and the reference strains all belonged to $P$. fermentans, but the DGGE results showed the different migration of bands. This phenomenon clearly indicated that both HY3 and TY3 were different subspecies from $P$. fermentans var. fermentans. 
Table 1. Identification of yeast species isolated from starters by biochemical method and sequence information from the $26 \mathrm{~S}$ rDNA PCR product

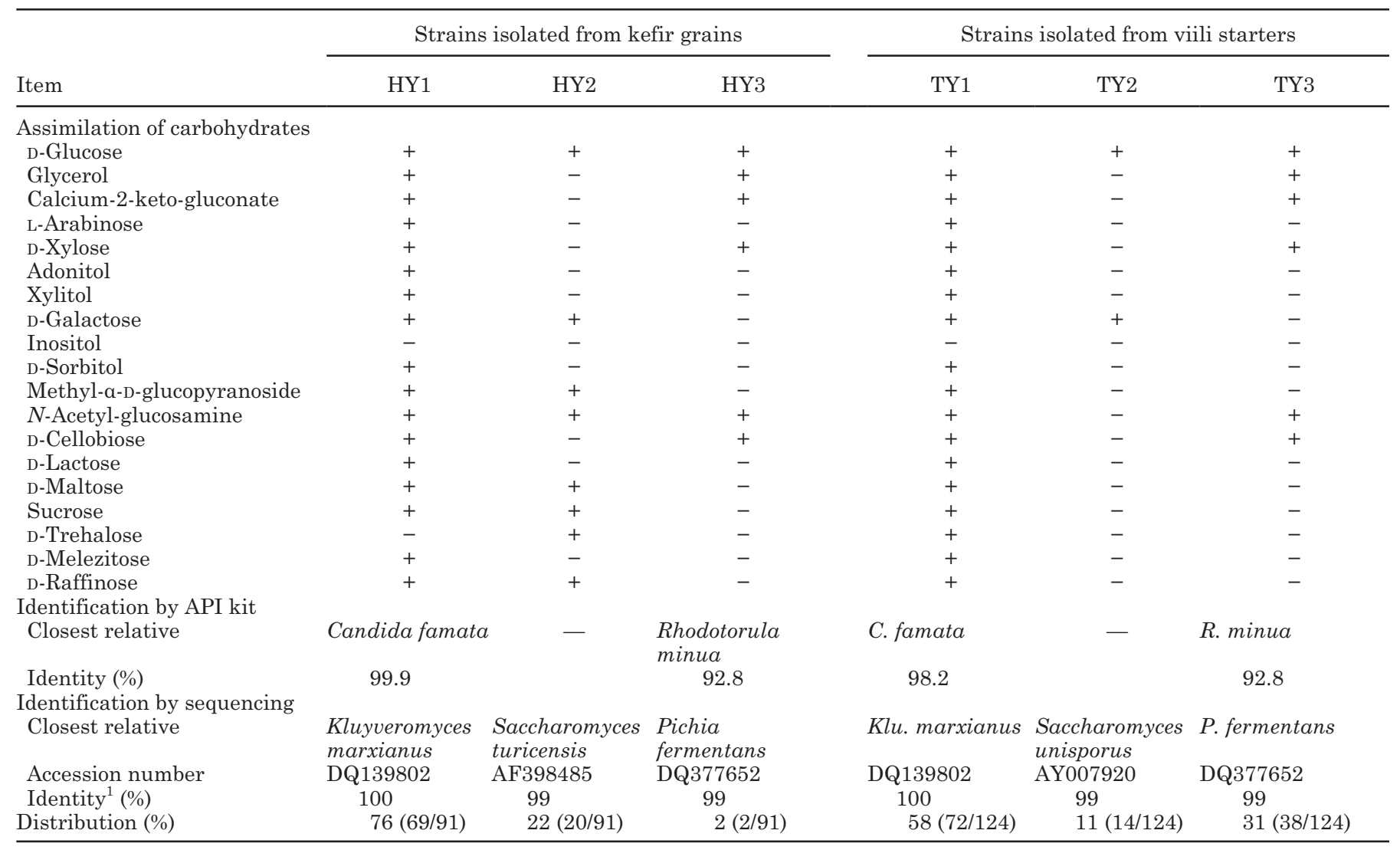

${ }^{1}$ Identical nucleotide percentage in the sequence obtained from the agarose band and the sequence obtained found in the NCBI database.

Both $S$. turicensis and $P$. fermentans identified in our kefir grains were lactose-negative yeasts (Table 1), which have to depend on lactic acid bacteria to hydrolyze lactose. Conversely, Klu. marxianus was a lactosepositive yeast. Simova et al. (2002) indicated that Klu. marxianus isolated from kefir grains was distinguished by occurring with lactose-negative yeasts, which was also confirmed in this study. Participation of $\mathrm{Klu}$. marxianus in the kefir starters ensures metabolism of lactose through alcohol fermentation and formation of the typical yeasty flavor. Besides Klu. marxianus, the lactose-negative yeasts in the formation of the kefir flavor also play very important roles. Simova et al. (2002) also reported that the typical yeasty flavor and aroma was absent in the kefir when the kefir was produced by Klu. marxianus only.

All 3 yeasts isolated from our kefir grains were also found in European kefir grains (Rohm et al., 1992; Wyder and Puhan, 1997; Wyder et al., 1999). Farnworth and Mainville (2003) concluded that the list of microorganisms in kefir grains from different parts of the world would not be very extensive, because a contaminant species would probably not survive due to the production of compounds by the symbiotic flora of kefir. On the other hand, Garbers et al. (2004) and Witthuhn et al. (2004) employed PCR-DGGE with DNA sequencing and the API kit method, respectively, to identify yeasts in South African kefir grains. None of the yeast strains in 8 different kefir grains from South Africa were identified in Taiwanese kefir (Garbers et al., 2004; Witthuhn et al., 2004). These differences could be explained mainly by the different origins and identification methods.

Most traditional viili cultures also contain yeast species (Kontusaari et al., 1985; Shurtleff and Aoyagi, 2004), but the various species were not specified in these studies. It is worth noting that $K l u$. marxianus with a group of lactose-negative yeasts $P$. fermentans and $S$. unisporus present in viili were not reported before.

\section{Distribution}

The Harrison disc method used for random statistical selection of representative colonies allowed for the calculation of the percentage distribution of the yeast found in kefir grains and viili starters. Table 1 depicts the percentage of the prevalent yeast population pres- 


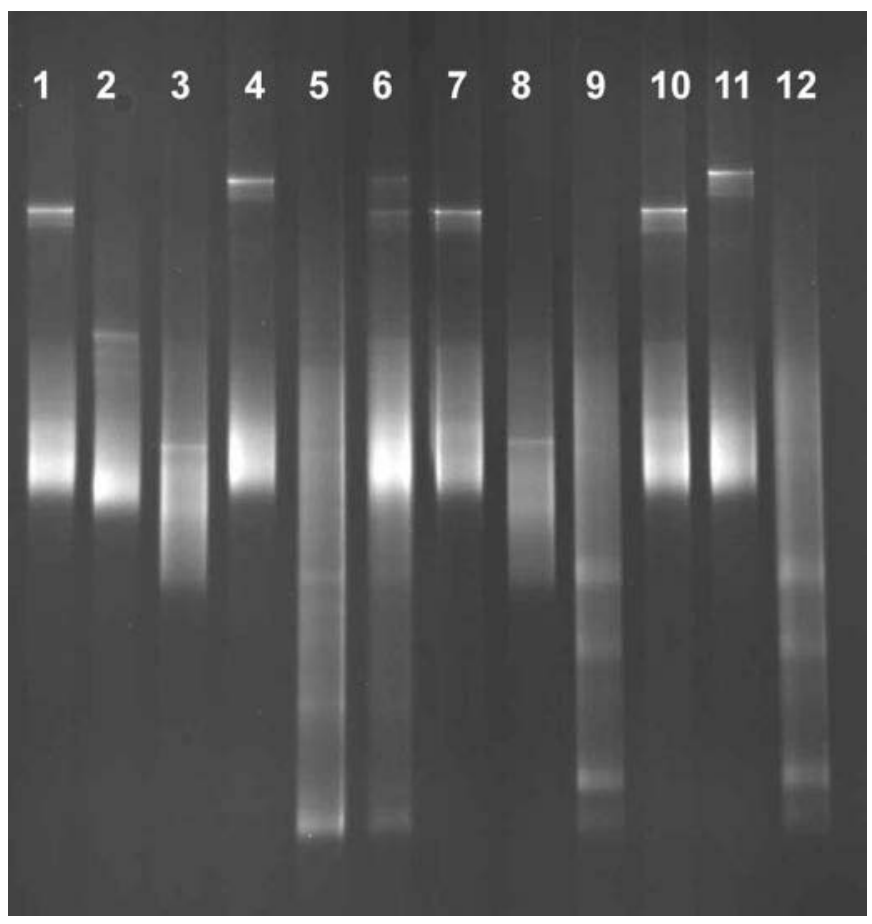

Figure 3. Denaturing gradient gel electrophoresis profiles of the yeast references and isolates from kefir grains (HY1, 2, and 3) and viili starters (TY1, 2, and 3) using a denaturing gradient from 30 to $55 \%$ of urea and formamide. Lane $1=$ Kluyveromyces marxianus var. marxianus BCRC 20330; lane $2=$ Saccharomyces cerevisiae BCRC 21685; lane 3 = Saccharomyces turicensis BCRC 22968; lane $4=$ Saccharomyces unisporus BCRC 21975; lane $5=$ Pichia fermen tans var. fermentans BCRC 22090; lane $6=$ mixed reference; lane 7 = HY1; lane 8 = HY2; lane 9 = HY3; lane $10=\mathrm{TY} 1$; lane $11=\mathrm{TY} 2$; lane $12=\mathrm{TY} 3$

ent in kefir grains and viili starters. Kluveromyces marxianus accounted for $76 \%$ of the total isolates, constituting the most dominant yeast found in kefir grains, followed by $S$. turicensis (22\%) and P. fermentans (2\%). In viili starters, Klu. marxianus accounted for $58 \%$ of the total isolates, followed by P. fermentans (31\%) and $S$. unisporus (11\%). Because Klu. marxianus can utilize both lactose and galactose as its carbon source (Table 1), this yeast can multiply well in milk. This may explain why this strain was the primary yeast in both culture samples. In addition, both $P$. fermentans and $S$. unisporus, the least common yeasts isolated in kefir grains and viili starters, respectively, could not be identified by culture-independent methods using PCRDGGE. This finding suggests that the species with larger populations in the mixture might give greater amounts of template DNA, and therefore make the detection of minor species difficult.

Several factors affected the distribution of the microorganisms in kefir grains. The microorganism profile of the final product does not necessarily parallel that of the grains because of conditions ( $\mathrm{pH}$ and other) during the fermentation process. Witthuhn et al. (2005) reported that different packaging conditions also affect the microbial community of kefir grains.

\section{CONCLUSIONS}

Using a combination of conventional microbiological cultivation with PCR-DGGE could successfully identify 4 yeast species from both cultures in Taiwan. Kluveromyces marxianus, $S$. turicensis, and $P$. fermentans were found in Taiwanese kefir grains with 76, 22, and $2 \%$ distribution, respectively, whereas Klu. marxianus, $S$. unisporus, and $P$. fermentans were identified in viili starters with 58,11 , and $31 \%$ distribution, respectively. Furthermore, a culture-independent method was applied to identify the viili and kefir yeasts using DGGE. Pichia fermentans in kefir grains and S. unisporus in viili starter were not identified. This result confirms that only the predominant yeast populations in these starters could be identified. This is the first report demonstrating that a combination of conventional microbiological cultivation, PCR-DGGE, and sequencing methods could successfully identify species of yeast and allow the study of their distribution in kefir grains and viili starters. This is also the first research showing the yeast species and their distribution in viili starter.

\section{ACKNOWLEDGMENTS}

The authors thank the National Science Council in Taiwan for their support of this research.

\section{REFERENCES}

Beh, A. L., G. H. Fleet, C. Prakitchaiwattana, and G. M. Heard 2006. Evaluation of molecular methods for the analysis of yeasts in foods and beverages. Adv. Exp. Med. Biol. 571:69-106.

Boutrou, R., and M. Guéguen. 2005. Interest in Geotrichum candidum for cheese technology. Int. J. Food Microbiol. 102:1-20.

Cheirsilp, B., H. Shimizu, and S. Shioya. 2003. Enhanced kefiran production by mixed culture of Lactobacillus kefiranofaciens and Saccharomyces cerevisiae. J. Biotechnol. 100:43-53.

Chen, H. C., C. W. Lin, and M. J. Chen. 2006. The effects of freeze drying and rehydration on survival of microorganisms in kefir. Asian-australas. J. Anim. Sci. 19:126-130.

Cocolin, L., D. Aggio, M. Manzano, C. Cantoni, and G. Comi. 2002. An application of PCR-DGGE analysis to profile the yeast population in raw milk. Int. Dairy J. 12:407-411.

Cocolin, L., L. F. Bisson, and D. A. Mills. 2000. Direct profiling of the yeast dynamics in wine fermentations. FEMS Microbiol. Lett. 189:81-87.

Davey, K. G., P. M. Chant, C. S. Downer, C. K. Campbell, and D. W. Warnock. 1995. Evaluation of the Auxacolor system, a new method of clinical yeast identification. J. Clin. Pathol. 48:807809.

Dharmawan, J., I. S. Surono, and L. Y. Kunm. 2006. Adhesion properties of indigenous dadih lactic acid bacteria on human intestinal mucosal surface. Asian-australas. J. Anim. Sci. 19:751-755.

Ercolini, D. 2004. PCR-DGGE fingerprinting: Novel strategies for detection of microbes in food. J. Microbiol. Methods 56:297314 . 
Farnworth, E. R., and I. Mainville. 2003. Kefir: A fermented milk product. Pages 77-112 in Handbook of Fermented Functional Foods. E. R. Farnworth, ed. CRC Press, London, UK.

Fasoli, S., M. Marzotto, M. Rizzotti, L. Rossi, F. Dellaglio, and S. Torriani. 2003. Bacterial composition of commercial probiotic products as evaluated by PCR-DGGE analysis. Int. J. Food Microbiol. 82:59-70.

Felske, A., A. D. L. Akkermans, and W. M. de Vos. 1998. Quantification of $16 \mathrm{~S}$ rRNAs in complex bacterial communities by multiple competitive reverse transcription-PCR in temperature gradient gel electrophoresis fingerprintings. Appl. Environ. Microbiol. 64:4581-4587.

Fenn, J. P., H. Segal, B. Barland, D. Denton, J. Whisenant, H. Chun, K. Christofferson, L. Hamilton, and K. Carroll. 1994. Comparison of updated Vitek yeast biochemical card and API 20C yeast identification systems. J. Clin. Microbiol. 32:1184-1187.

Fujisawa, T., S. Adachi, T. Toba, K. Arihara, and T. Mitsuoka. 1988. Lactobacillus kefiranofaciens sp. nov. isolated from kefir grains. Int. J. Syst. Bacteriol. 38:12-14.

Garbers, I. M., T. Z. Britz, and R. C. Witthuhn. 2004. PCRbase denaturing gradient gel electrophoretictypification and identification of the microbial consortium present in kefir grains. 2004. World J. Microbiol. Biotechnol. 20:687-693.

Harrigan, W. F. 1998. Sampling methods for the selection and examination of microbial colonies. Pages 89-91 in Laboratory Methods in Food Microbiology. 3rd ed. Academic Press, San Diego, CA

Kitazawa, H., T. Itoh, Y. Tomioka, M. Mizugaki, and T. Yamaguchi. 1996. Induction of IFN-Y and IL-1 $\alpha$ production in macrophages stimulated with phosphopolysaccharide produced by Lactococcus lactis ssp. cremoris. Int. J. Food Microbiol. 31:99-106.

Kitazawa, H., T. Toba, T. Itoh, N. Kumano, S. Adachi, and T. Yamaguchi. 1991. Antitumoral activity of slime-forming, encapsulated Lactococcus lactis ssp. cremoris isolated from Scandinavian ropy sour milk "viili." Anim. Sci. Technol. 62:277283.

Kitazawa, H., T. Yamaguchi, M. Miura, T. Saito, and T. Itoh. 1993. B-cell mitogen produced by slime-forming encapsulated Lactococcus lactis ssp. cremoris isolated from ropy sour milk, viili. J. Dairy Sci. 76:1514-1519.

Kontusaari, S.I.,P.T. Vuokila, and R.I.Forsén. 1985.Immunochemical study of Triton X-100-soluble surface components if slimeforming, encapsulated Streptococcus cremoris from the fermented milk product viili. Appl. Environ. Microbiol. 50:174-176.

Leporanta, K. 2003. Viili and Långfil—Exotic fermented products from Scandinavia. Valio Foods \& Functionals. Feb:3-5. http://www. valio.fi/portal/page/portal/valiocom/Valio_Today/Publications/ valio_foods_functionals05102006130335/2003.pdf

Lin, C. W., H. L. Chen, and J. R. Liu. 1999. Identification and characterisation of lactic acid bacteria and yeasts isolated from kefir grains in Taiwan. Aust. J. Dairy Technol. 54:14-18.

Liu, J. R., S. Y. Wang, M. J. Chen, H. L. Chen, P. Y. Yueh, and C. W. Lin. 2006a. Hypocholesterolemic effects of milk-kefir and soymilk-kefir in cholesterol-fed hamsters. Br. J. Nutr. 95:939946.

Liu, J. R., S. Y. Wang, Y. Y. Lin, and C. W. Lin. 2002. Antitumor activity of milk kefir and soy milk kefir in tumor-bearing mice. Nutr. Cancer 44:182-187.

Liu, J. R., S. Y. Wang, Y. Y. Lin, C. W. Lin, M. J. Chen, P. Y. Yueh, and C. W. Lin. 2006b. The anti-allergenic properties of milk kefir and soymilk kefir and their beneficial effects on the intestinal microflora. J. Sci. Food Agric. 86:2527-2533.

Masoud, W., L. B. Cesar, L. Jespersen, and M. Jakobsen. 2004. Yeast involved in fermentation of Coffea arabica in East Africa determined by genotyping and by direct denaturating gradient gel electrophoresis. Yeast 21:549-556.

Mistry, V. V. 2004. Fermented liquid milk products. Pages 1-16 in Handbook of Food and Beverage Fermentation Technology. Y. H. Hui, L. Meunier-Goddik, A. S. Hansen, J. Josephsen, W. Nip, P. S. Stanfield, and F. Toldrá, ed. Marcel Dekker Inc., New York, NY.
Muyzer, G., and K. Smalla. 1998. Application of denaturing gradient gel electrophoresis (DGGE) and temperature gradient gel electrophoresis (TGGE) in microbial ecology. Antonie Van Leeuwenhoek 73:127-141.

Nakajima, H., Y. Suzuki, H. Kaizu, and T. Hirota. 1992. Cholesterol lowering activity of ropy fermented milk. J. Food Sci. 57:13271329 .

Nielsen, D. S., S. Hønholt, K. Tano-Debrah, and L. Jespersen. 2005. Yeast populations associated with Ghanaian cocoa fermentations analysed using denaturing gradient gel electrophoresis (DGGE). Yeast 22:271-284.

O'Donnell, K. 1993. Fusarium and its near relatives. Pages 225-233 in The Fungal Holomorph: Mitotic, Meiotic and Pleomorphic Speciation in Fungal Systematics. D. R. Reynolds and J. W. Taylor, ed. CAB International, Wallingford, UK.

Pintado, M. E., J. A. Lopes da Silva, P. B. Fernandes, F. X. Malcata, and T. A. Hogg. 1996. Microbiological and rheological studies on Portuguese kefir grains. Int. J. Food Sci. Technol. 31:15-26.

Prakitchaiwattana, C. J., G. H. Fleet, and G. M. Heard. 2004. Application and evaluation of denaturing gradient gel electrophoresis to analyse the yeast ecology of wine grapes. FEMS Yeast Res. 4:865-877.

Ramani, R., D. Gromadzkis, H. Pincus, I. F. Salkin, and V. Chaturvedi. 1998. Efficacy of API 20C and ID 32C systems for identification of common and rate clinical yeast isolates. J. Clin. Microbiol. 36:3396-3398.

Renouf, V., O. Claisse, and A. Lonvaud-Funel. 2007. Inventory of the wine microbial consortia. Appl. Microbiol. Biotechnol. 75:149164.

Rohm, H., F. Eliskases-Lechner, and M. Bräuer. 1992. Diversity of yeasts in selected dairy products. J. Appl. Bacteriol. 72:370376.

Ruas-Madiedo, P., M. Gueimonde, G. C. de los Reyes-Gavilán, and S. Salminen. 2006. Short communication: Effect of exopolysaccharide isolated from "viili" on the adhesion of probiotics and pathogens to intestinal mucus. J. Dairy Sci. 89:2355-2358.

Shurtleff, W., and A. Aoyagi. 2004. History of fermented soymilk and its products. Pages in History of Soybeans and Soyfoods: 1100 B.C. to the 1980s. W. Shurtleff and A. Aoyagi, ed. Soyfoods Center, Lafayette, CA.

Simova, E., D. Beshkova, A. Angelov, Ts. Hristozova, G. Frengova, and Z. Spasov. 2002. Lactic acid bacteria and yeasts in kefir grains and kefir made from them. J. Ind. Microbiol. Biotechnol. $28: 1-6$.

Theunissen, J., T. J. Britz, S. Torriani, and R. C. Witthuhn. 2005. Identification of probiotic microorganisms in South African products using PCR-based DGGE analysis. Int. J. Food Microbiol. 98:11-21.

Tsutsui, S., M. Kikuchi, S. Takahashi, and H. Ariga. 1998. Finland ropy sour milk "viili", analyzed for its acidity, viscidity and constitution. J. Rakuno Gakuen Univ. 22:231-237.

Walter, J., G. W. Tannock, A. Tilsala-Timisjarvi, S. Rodtong, D. M. Loach, K. Munro, and T. Alatossava. 2000. Detection and identification of gastrointestinal Lactobacillus species by using denaturing gradient gel electrophoresis and species-specific PCR primers. Appl. Environ. Microbiol. 66:297-303.

Witthuhn, R. C., T. Schoeman, and T. J. Britz. 2004. Isolation and characterization of the microbial population of different South African kefir grains. Int. J. Dairy Technol. 57:33-37.

Witthuhn, R. C., T. Schoeman, and T. J. Britz. 2005. Impact of preservation and different packaging conditions on the microbial community and activity of kefir grains. Food Microbiol. 22:337344.

Wyder, M. T., L. Meile, and M. Teuber. 1999. Description of Saccharomyces turicensis sp. nov., a new species from kefyr. Syst. Appl. Microbiol. 22:420-425.

Wyder, M. T., and Z. Puhan. 1997. A rapid method for identification of yeasts from kefir at species level. Milchwissenschaft 52:327330. 